\title{
O ensino de História na Ditadura CiVIL-MilitaR COM A INSTITUCIONALIZAÇão DOS EsTUdOS SOCIAIS
}

\section{THE TEACHING OF HISTORY IN THE CIVIL-MILITARY DICTATORSHIP WITH THE INTEGRATION IN THE AREA OF SOCIAL STUDIES}

\author{
lêda Viana ${ }^{a}$
}

Resumo O artigo se refere ao contexto da Ditadura Civil-Militar no Brasil (1964-1985) e às implicações da Lei 5.692/71 no ensino brasileiro, especialmente com relação à disciplina escolar História, que passa a ser integrada a uma área de ensino, junto com a Geografia, qual seja Estudos Sociais, pelo Decreto 853/71. O foco da análise foram as práticas escolares da área de Estudos Sociais, com o intuito de dar inteligibilidade a movimentos realizados no interior de algumas escolas municipais de Curitiba, procurando deslocar o olhar do lugar próprio (campo político) para o lugar praticado (campo escolar), investigando as reações dos professores municipais diante das diretrizes educacionais, na perspectiva certeauniana (1994), que recusa a visão dos indivíduos como meros consumidores de bens culturais. Como objeto específico da investigação tomou-se a institucionalização dos Estudos Sociais naquelas escolas, por meio de um projeto alternativo ao oficial, o Projeto de Estudos Sociais a partir da longa duração (1975-1985), fundamentado na historiografia francesa, que privilegiava a interdisciplinaridade, entre outros aspectos, o que contribuiu para a legitimação daquele projeto de integração de algumas áreas do conhecimento. A história oral e relatórios institucionais e escolares serviram de aporte metodológico para a pesquisa, cujos resultados revelam que nem sempre as estratégias políticas do regime militar foram cumpridas fielmente, havendo, no campo educacional, por exemplo, uma

a Doutora em Educação e mestre em História Social pela Universidade Federal do Paraná. Professora no Programa de Mestrado em Educação da Universidade Tuiuti do Paraná. O artigo foi elaborado a partir de dados parciais coletados para a tese de doutorado da autora, com o título “Artes de fazer' na reforma escolar: o projeto de estudos sociais a partir da longa duração em Curitiba (décadas de 1970-1980)”, defendida no Curso de Pós-Graduação em Educação, linha de pesquisa História e Historiografia da Educação, Setor de Educação da Universidade Federal do Paraná, em 2006. 
margem de negociação e resistência que permitiu aos educadores enfrentarem esse período por meio de variadas táticas.

Palavras-chave Ditadura Civil-Militar; Lei 5.692/71; Estudos Sociais; Michel de Certeau; práticas escolares.

Abstract The article refers to the context of the Civil-Military Dictatorship in Brazil (1964-1985) and the implications of Law 5692/71 in Brazilian education, especially with regard to the subject of History, which is integrated into a teaching area, along with Geography - Social Studies - by Decree 853/71. The focus of the analysis were school practices in the area of Social Studies, as an attempt to clarify the movements accomplished inside some local schools in Curitiba. To this end, we will try to direct our regard from the place itself (political field) towards the practiced place (school field), investigating local teachers' reactions towards educational guidelines from a de Certeaunian perspective (1994) which refuses the view of individuals as mere consumers of cultural goods. The specific object of this research was the institutionalization of Social Studies in those schools through an alternative to the official project: the Social Studies project based on the long term (1975-1985), influenced by the work of the French historiography, which privileged, among other things, interdisciplinarity, and contributed to the legitimation of the integration project of some areas of knowledge. Oral history and institutional and school reports served as a methodological approach to the research. The results show that the political strategies of the military regime were not always fulfilled faithfully, especially in the educational field, for example, where a margin of negotiation and resistance, allowed educators to face this period through various tactics.

Keywords Civil-Military Dictatorship; Law 5692/71; Social Studies; Michel de Certeau; school practices.

\section{INTRODUÇÃO}

Este artigo trata do contexto da Ditadura Civil-Militar ${ }^{1}$ (1964-1985) e das implicações da Lei 5.692/71 no ensino brasileiro, especialmente com relação à

1 A opção pela designação Ditadura Civil-Militar decorre de discussões que vêm sendo realizadas por pesquisadores desse contexto histórico, os quais alertam para a simplificação e dicotomização da expressão Ditadura Militar para esse período, que foi muito mais complexo, pois contou com o apoio direto ou a omissão de diferentes segmentos da sociedade civil, além da população de forma geral, satisfeitos pelo menos com os efeitos do crescimento econômico, segundo Gonçalves (2012). 
disciplina escolar História, que passa a ser integrada a uma área de ensino, junto com a Geografia, qual seja Estudos Sociais, pelo Parecer 853/71.

A Lei 5.692/71 foi criada em um contexto paradoxal, ao mesmo tempo autoritário e repressivo, alvo de contestações e resistências, mas também de euforia e acordos tácitos por várias razões, especialmente em função do crescimento econômico e de seus reflexos nos campos de emprego, urbanização e cultura do país, que contribuíram significativamente para a omissão, a adesão e o apoio de uma parte da população às diretrizes desenvolvimentistas do governo. A repressão e a censura eram inegáveis, naquele período, mas somente as percebiam as pessoas que eram seu alvo direto e que consistiam, relativamente, em uma minoria, se comparada ao total da população. Esta, em sua maioria, não percebeu aquilo que a atingia, não se incomodou com isso ou aceitou passivamente, diante dos efeitos, por exemplo, do milagre econômico (Gonçalves, 2012, p. 10).

Este panorama traz novas leituras e questionamentos sobre aquele período. Em relação à educação e ao ensino de História, ainda são poucas as pesquisas que permitem entender como a escola e seus diferentes interlocutores reagiram em relação às diretrizes dos governos militares.

Desse modo, este artigo visa analisar o período, focando principalmente as práticas escolares dos Estudos Sociais, com o intuito de conferir inteligibilidade a movimentos realizados no interior das escolas municipais de Curitiba, que podem ser compreendidos como táticas sutis das práticas ordinárias, isto é, apropriações e usos dos praticantes frente às estratégias políticas. Para isso, procurou-se deslocar o olhar do lugar próprio para o lugar praticado, analisando as reações dos professores municipais diante das diretrizes educacionais, na perspectiva certeauniana (1994), que recusa a visão dos indivíduos como meros consumidores de bens culturais.

O lugar próprio, para Certeau (1994, p. 202), é onde se constitui o saber e o poder - o lugar dos "fortes" -, que, por sua posição, têm uma visão macro da situação, permitindo-lhes o estabelecimento de estratégias; e o lugar praticado é aquele no qual lutam os "fracos", em que prevalece a ausência de dispositivos de poder panópticos, portanto, ali os praticantes, por não terem o domínio do lugar, só podem contar com o tempo, a ocasião e a perspicácia para atingir seus objetivos por meio de táticas sutis.

Mudanças paradigmáticas na historiografia da educação, com a valorização de outras fontes, como as escolares, permitiram o deslocamento do olhar investigativo para o interior da escola, para as práticas, os rituais e os saberes que circulam em seu cotidiano. É nessa perspectiva que este artigo se posiciona, tomando como 
referência a História Cultural, um dos campos de estudo que contribui para a valorização da pesquisa histórica sobre o funcionamento escolar, o que originou o conceito de cultura escolar ${ }^{2}$. Assim, definiu-se como problemática pensar de que modo, no processo de reformas escolares, os textos prescritivos são fabricados estrategicamente em um determinado lugar de saber e poder e apropriados e praticados (possivelmente de forma tática) por diferentes agentes históricos no interior das escolas.

Como objeto da investigação tomou-se a reforma curricular implantada com a Lei 5.692/71 e a institucionalização dos Estudos Sociais, no período do Regime Civil-Militar, nas escolas municipais de Curitiba, porque, naquela rede de ensino público, tal implantação ocorreu por meio de um projeto alternativo ao oficial, o Projeto de Estudos Sociais a partir da longa duração (1975-1985), fundamentado teoricamente na obra do historiador francês Fernand Braudel, um dos historiadores que liderou o movimento historiográfico da revista de Annales.

A reconstituição das práticas escolares, por meio da memória dos professores municipais e do exame de relatórios institucionais, proporcionou visibilidade à invenção do cotidiano (CERTEAU, 1994). As fontes orais tiveram um papel importante na busca por inteligibilidade histórica, envolvendo a noção de memória enquanto representação. Para Certeau, a memória é a chave para a compreensão dos movimentos táticos e uma presença à pluralidade de tempos, a qual, graças à capacidade de acumular experiências, permanece oculta - como "escrituras invisíveis" - até o instante em que se revela no "momento oportuno" como lembrança. Ela é representação, mas também é prática, pois a construção de sentido ocorre na relação com o outro (CERTEAU, 1996, p. 63).

A historiografia sobre o ensino de História, no contexto da reforma educacional dos anos 1970, tem contribuído para a construção de algumas representações ${ }^{3}$ desse ensino, que, neste momento, sintetizamos em duas versões:

- a do esvaziamento de conteúdos oriundos da ciência de referência História -, após a implantação dos Estudos Sociais ${ }^{4}$, com a integração das

2 Cultura escolar para Julia (2001) não envolve apenas as normas produzidas externamente às escolas, para discipliná-las, mas se refere às práticas que ocorrem no interior das escolas, nas quais poderíamos incluir os rituais, os saberes, o uso dos espaços e tempos escolares, os valores que circulam no dia a dia da instituição educativa e que contribuem para a formação do sujeito social, entre outros aspectos.

3 Roger Chartier compreende as representações sociais como esquemas ou conteúdos de pensamentos que, embora enunciados de modo individual, são, na verdade, condicionamentos não conscientes e interiorizados, que fazem com que um grupo ou determinada sociedade partilhe um sistema de representações e um sistema de valores comuns (CHARTIER, 1986)

4 Consultar: Fenelon (1984), Fonseca (1995) e Bittencourt (1995). 
áreas de conhecimento. Nessa leitura, a transposição didática ${ }^{5}$ realizada nos currículos escolares de Estudos Sociais teria promovido o distanciamento que passou a existir entre os saberes escolares e os saberes acadêmicos ${ }^{6}$;

- a da permanência dos referenciais teórico-metodológicos tradicionais da ciência de referência, quando da institucionalização dos Estudos Sociais: mantendo esses fundamentos inalterados, permaneceu a primazia dos aspectos políticos, datas, personagens heróicos, batalhas, portanto, a perspectiva da História linear, evolucionista, factual, sem grandes mudanças de conteúdo (NADAI, 1985/1986, p. 110)7.

Diante dessas representações contraditórias, o interesse em analisar a complexidade daquele contexto cultural e político, muito mais ampla do que se tem pensado, mobilizou a reflexão sobre o significado histórico da implantação do Projeto de Estudos Sociais a partir da longa duração ${ }^{8}$, nas escolas municipais de Curitiba, principalmente por nele se identificar a preocupação de realizar a aproximação da escola à academia e do saber escolar ao saber científico, pela mediação de agentes históricos externos à escola, interferindo na produção e legitimação dos saberes escolares. $\mathrm{O}$ aporte teórico-metodológico da historiografia francesa, centrado em Fernand Braudel ${ }^{9}$, propunha a aproximação com as Ciências Sociais, o que o legitimava como fundamento para a proposta interdisciplinar de Estudos Sociais, naquele Projeto.

\section{A IMPLANTAÇÃO DOS ESTUDOS SOCIAIS NAS ESCOLAS MUNICIPAIS DE CURITIBA}

Este processo, após a Lei 5.692/71 e o Parecer 853/71, teria ocorrido por meio de dois projetos educativos que tiveram existência paralela. Primeiro, o Plano Curricular da Diretoria de Educação, elaborado estrategicamente por técnicos

5 Chevallard (1991) explica a transposição didática como a necessidade de estabelecer a relação entre o saber acadêmico e o saber escolar, cabendo à didática evitar o distanciamento entre ambos. Tal perspectiva recebe críticas por conceber o processo de produção do saber como uma forma de conhecimento descontextualizado de seu processo de criação e acentuar a hierarquização de saberes como base para a constituição de conhecimento para a sociedade, mas foi essa concepção que de certo modo, avant la letre, norteou o Projeto de Estudos Sociais a partir da longa duração.

6 O ensino tradicional de História, segundo Nadai (1992/1993), apesar das críticas realizadas a partir do movimento renovador da educação, articulava-se coerentemente com um determinado referencial teórico-metodológico da ciência de referência em sua vertente positivista.

7 Além de Nadai (1985/1986), consultar Schmidt e Cainelli (2004).

8 Neste texto, a menção ao Projeto de Estudos Sociais a partir da longa duração será feita sempre pelo termo Projeto.

9 A concepção do Projeto e sua organização em conteúdos curriculares tiveram como referencial as obras de Braudel (1970; 1972). 
municipais, portanto, estruturado em um lugar próprio, no campo político, fornecendo orientações para todas as áreas de ensino e, no que concerne aos Estudos Sociais (integrado basicamente por História e Geografia), não apresentando diferenças importantes em relação aos currículos anteriores. Segundo, o Projeto de Estudos Sociais a partir da longa duração, elaborado taticamente ${ }^{10}$, no campo acadêmico, por intelectuais da Universidade Federal do Paraná ${ }^{11}$, implantado em algumas escolas municipais sob o aval da Diretoria de Educação ${ }^{12}$.

A participação dos intelectuais sinalizou, para a hipótese geral da investigação, que o aproveitamento de uma brecha no poder por parte desses agentes permitiu-lhes - por meio da perspectiva de mudança educacional (PoPkEwiTz, 1997) e operando em um quadro de movimentos táticos (CERTEAU, 1994) à política educacional - as condições para estabelecer, ao lado do projeto educativo oficial, uma experiência alternativa, coerente com suas apropriações das determinações políticas. Pensar as políticas educacionais é refletir não apenas em sua natureza de controle e de regulação social (PoPKEwITz, 1997), objetos da esfera estratégica de poder, mas também deslocar o pensamento para as táticas operadas nos estratos de não poder, ou seja, refletir sobre como se realiza o processo de apropriação ${ }^{13}$ das ordenações superiores pelos usuários, os quais colocam em jogo atitudes de adesão, instauram negociações, constituem espaços, enquanto lugares praticados, em uma rede de lugares e relações que produzem poder e saber (CERTEAU, 1994) e onde são constituídas as representações sociais.

As primeiras escolas envolvidas no Projeto foram: em 1975, Omar Sabbag (nordeste) e Albert Schweitzer (sudoeste); e, em 1976, Papa João XXIII (oeste) e Júlia Amaral Di Lena (norte). Aos poucos, algumas unidades que implantavam as séries finais do $1^{\circ}$ grau, em atendimento à reforma, aderiram ao Projeto, assim

10 Embora o Projeto seja de autoria de professores da Universidade Federal do Paraná (UFPR), intelectuais, portanto, externos às escolas municipais, eles o elaboraram também taticamente frente à estratégia política de institucionalização dos Estudos Sociais pelo regime civil-militar, como se pretendeu demonstrar neste artigo. No caso de intelectuais, Certeau (1994) compreende que eles possam ocupar tanto o lugar próprio como o lugar praticado, utilizando-se de estratégias ou táticas, de acordo com o lugar em que estejam posicionados contingencialmente.

11 Os elaboradores do Projeto de Estudos Sociais a partir da longa duração foram os historiadores do Departamento de História da UFPR, que deveriam implantá-lo em dois anos (1975-1976). O Ministério de Educação (MEC) convidou representantes de universidades do país a apresentarem proposta para a institucionalização dos Estudos Sociais, possivelmente como estratégia de legitimação da reforma que se implantava.

12 Apenas o Projeto de Estudos Sociais a partir da longa duração é objeto de análise neste artigo.

13 A noção de apropriação para Chartier (1991, p. 180) visa realizar "uma história social dos usos e das interpretações, referidos as suas determinações fundamentais e inscritas nas práticas específicas que a produzem”. Seu significado indica duas dimensões: a ênfase nas interpretações, remetendo ao conceito de representações sociais; e o realce aos usos, orientando a investigação para as práticas. É através da apropriação que ocorre a operação de sentido por parte dos usuários. 
como escolas de $1^{\mathrm{a}}$ a $4^{\mathrm{a}}$ série, com o propósito de unificar o ensino nessa área de conhecimento, desde as séries iniciais.

A visão panóptica que a História proporciona permite afirmar a permanência do Projeto por cerca de uma década, apesar de apontar um declínio relativo ao longo do tempo. Em 1979, atingia 32,2\% das escolas municipais (CuRITIBA, 1979a, p. 6-7), e, em 1982, o índice havia caído para 21,5\% (CuritibA, 1982, p. 12, 17). Há registros do Projeto até meados da década de 1980, quando, sob o impacto de movimento local (que se incorporava ao movimento realizado no plano nacional) pelo retorno da História e da Geografia como disciplinas autônomas no currículo de $1^{\circ}$ grau, o Conselho Estadual de Educação aprovou parecer, argumentando que já existia o amparo legal para trabalhar os Estudos Sociais com as disciplinas separadas, desde que se "respeitasse o princípio de integração que fundamenta o currículo"14 (PARANÁ, CEE. Parecer 332/84, 1983, p. 9).

Em decorrência, a área de Estudos Sociais não seria extinta, mantendo-se sua rubrica, mas História e Geografia poderiam ser trabalhadas separadamente, dando-se legitimidade a uma situação que, de fato, já existia na prática escolar em muitas escolas.

Em 1986, Resolução do Conselho Federal de Educação aprovou a separação definitiva das disciplinas História e Geografia (BRASIL. CFE. Parecer 785/86, anexo à Resolução 06/86) e, a seguir, o Conselho Estadual de Educação aprovou a Deliberação 0047/87, que estabelecia "Normas para reformulação do Núcleo Comum para os Currículos do $1^{\circ}$ e $2^{\circ}$ graus, no Sistema Estadual”.

Em 1988, foi publicado o "Currículo Básico - Uma contribuição para a Escola Pública Brasileira” (CuritiBA, 1988), para o município de Curitiba, o qual propõe uma nova concepção das áreas de estudo, procurando aproximar as disciplinas das ciências de referência.

Ora, diante disso, como a reforma dos anos 1970 se realizou efetivamente no interior das escolas municipais? Como a proposta de Estudos Sociais foi apropriada e colocada em prática pelos professores?

\section{AS ESTRATÉGIAS POLÍTICAS E AS PRÁTICAS ESCOLARES}

A eficácia da experiência alternativa foi procurada por meio de algumas medidas estratégicas gerais: a formulação de um currículo prescritivo (o Projeto de Estudos Socais a partir da longa duração), a formação continuada dos profes-

14 O amparo legal era dado pelo Parecer Federal 7.676/78. 
sores (ou treinamento, como se denominava na época) e um processo controlado de acompanhamento e avaliação. Neste artigo será discutido apenas o primeiro aspecto - o curricular.

As transformações pelas quais passavam as sociedades brasileira e paranaense, no contexto de desenvolvimento das relações do capitalismo industrial e urbano, não mais favoreciam o processo educacional e o ensino das humanidades, com base apenas na erudição e memorização. Ao contrário, impunham uma perspectiva de aprendizagem orientada para a capacidade de abstração, para a solução de problemas, captada pelos intelectuais ainda na esteira dos princípios da escola nova e sua tendência psicologista.

O Projeto tinha uma motivação contingencial: atender à ordenação legal, respondendo ao chamado do Ministério da Educação (MEC) ${ }^{15}$, porém adequando-a aos interesses acadêmicos, especialmente com relação à organização interdisciplinar de conteúdos, tendo a história como "fio condutor" (UFPR, 1976/1977, p. 43), de modo a intervir nas formas de apropriação de Estudos Sociais presentes até então.

O estudo [...] visa a corrigir as distorções do ensino tradicional de Estudos Sociais, principalmente em face dos dispositivos da Lei ${ }^{\circ} 5.692 / 71$, que pretendem, para algumas séries, a integração das matérias fornecidas aos alunos, a hierarquização dos pré-requisitos e das situações de aprendizagem, atendidas às noções prescritas pela Psicologia Evolutiva (UFPR, 1976/1977, p. 29).

Dentre os objetivos apresentados no Projeto, cabe ressaltar alguns que reforçam essa motivação de atender aos aspectos legais, mas taticamente articulando-os aos pressupostos teórico-metodológicos da História, fundamentada na concepção braudeliana da multiplicidade do tempo social e nos pressupostos psicopedagógicos da Psicologia Evolutiva, ordenando os conteúdos pelos "centros de interesse" do indivíduo, de acordo com sua faixa etária (UFPR, 1976/1977, p. 27-28).

a) Integrar os conteúdos programáticos da área de Estudos Sociais.

b) Hierarquizar os pré-requisitos e as situações de aprendizagem de acordo com a concepção "braudeliana" de História, para atender aos ditames do Parecer n ${ }^{\circ}$ 853/71, do Conselho Federal de Educação.

15 A professora Cecília Westphalen, coordenadora do Projeto pela UFPR e sua principal mentora, havia sido convidada pelo MEC, juntamente com outros representantes de universidades do país, para uma reunião em que se apresentaram propostas para a implantação dos Estudos Sociais. 
c) Permitir aos educandos uma visão mais próxima da realidade em que vivem em relação aos conteúdos de Estudos Sociais.

d) Fazer ver aos discentes que as Ciências do Homem se distinguem tão somente pelo objeto formal de seu estudo (UFPR, 1976/1977, p. 29).

A proposta pedagógica, como se observa, está pautada em pressupostos psicológicos que valorizam os interesses do aluno, seguindo a orientação pedagógica daquele contexto, embora o atendimento das transformações no perfil do aluno, com a massificação da escolarização, constituísse uma complexidade para a escola. A crença de que o ensino com base simplesmente na erudição não dá mais conta das necessidades sociais coloca como um imperativo a maior aproximação dos saberes escolares à realidade do aluno que tem acesso à escola. Daí, possivelmente, a articulação dos conteúdos, no Projeto, com os aspectos da vida cotidiana, conforme noção braudeliana de vida material ${ }^{16}$.

Cabe lembrar que na experiência do Projeto, embora a presença normalizadora seja forte, o caráter de modernização científica do ensino que busca a inclusão nos programas escolares de novidades provenientes de investigações das ciências de referência que, segundo Abud (1992/1993), está ausente nas propostas pedagógicas até então é o que mobiliza a ação reformadora dos intelectuais, ou seja, o seu desejo de modificação na tradição cultural a que estavam ligadas a História e seu ensino, cuja tendência historiográfica dominante entrara em declínio (a escola metódica ou positivista).

A análise dos conteúdos no Projeto impõe retomar um aspecto do currículo ressaltado por Apple, que o entende sempre como fruto de uma seleção: "nunca é um conjunto neutro de conhecimentos [...]. Ele é sempre [...] resultado da seleção de alguém, [...] acerca do que seja conhecimento legítimo. É produto de tensões, conflitos e concessões culturais, políticas e econômicas que organizam e desorganizam um povo" (Apple, 1995, p. 59). Assim, os conteúdos foram selecionados a partir da cultura acadêmica, considerando determinada tradição que valorizava as categorias das durações e dos ritmos temporais e a aproximação das Ciências Sociais (BRAUDEL, 1972), além das noções antropológicas de sobrevivência humana e suas respostas culturais - as necessidades básicas do homem (MALINOWSKI, 1962).

Do ponto de vista da concepção pedagógica, a expectativa do Projeto é "em termos dos conceitos que o aluno deverá elaborar, como primeiro passo para a

16 A vida material ou civilização, para Braudel (1970), envolvia três campos: o meio ambiente das sociedades; as bases materiais do cotidiano - alimentação, vestuário, moradia -; e as técnicas. 
formação de comportamentos mais complexos, bem como sua interiorização" "17, os quais devem ser trabalhados a partir dos "esquemas que o aluno já possui, pois a matéria atua sobre experiências que o próprio aluno vivencia, como indivíduo em sociedade" (UFPR, n. 3, 1976/1977, p. 22-23). Assim, os critérios de seleção de conteúdos foram definidos a partir da teoria de desenvolvimento dos estágios cognitivos piagetianos, com base em interpretação de Presseisen e D’Amico (1975, p. 24), que consideram a dimensão pessoal e social em sua relação com a faixa etária do aluno.

Na perspectiva do Projeto defende-se que o aluno deverá chegar ao conhecimento da realidade social e histórica não pelos fatos (curta duração), mas pela compreensão das estruturas (de longa duração), que estão presentes na vida humana e são pautadas pela vivência cotidiana; e pelas conjunturas (de média duração) que tornam compreensível o tempo social e individual (UFPR, 1976/1977, p. 18, 43). A opção pelo referencial teórico braudeliano permite trabalhar os conteúdos conceitualmente e a partir de temas próximos à realidade cotidiana do aluno, em seu caráter estrutural, mobilizando seu interesse, mas evitando o risco de um ensino anedotário.

O eixo temático central era o Homem vivendo em sociedade (UFPR, 1976/1977, p. 15, 18), a partir do qual foram selecionadas as matrizes curriculares ou geradoras (UFPR, 1976/1977, p. 16, 45). Primeiramente, indicaram-se o estudo das estruturas, as tendências seculares - de ritmo equivalente ao tempo geográfico -, tendências marcadas pelas permanências na vida cotidiana do homem, portanto, compreendidas como mais próximas da experiência do aluno e onde mais facilmente se apreendem as regularidades, as quais deveriam ser trabalhadas especialmente nas séries iniciais ( $1^{\mathrm{a}}$ a $4^{\mathrm{a}}$ séries), a partir de atividades e do eixo: "A vida de todos os dias", vista nas dimensões econômicas, históricas, geográficas, socioculturais e políticas (UFPR, 1976/1977, p. 46-57).

A seguir, propunha-se o estudo mais detalhado de "O homem brasileiro" e suas necessidades fundamentais como ser vivo e ser humano; as estruturas de longa duração, a serem trabalhadas nas séries finais ( $5^{\mathrm{a}}$ a $8^{\mathrm{a}}$ séries), pelas áreas de estudo, com o eixo desdobrado em estruturas etnoculturais; estruturas geográficas; e necessidades básicas: o aprovisionamento, a estrutura da habitação e a estrutura da veste (UFPR, 1976/1977, p. 46-57).

17 Esta concepção está fundamentada em Hirst e Peters (1972), acreditando que "não pode haver experiência ou conhecimento sem a aquisição dos conceitos pertinentes" (UFPR, 1976/1977, p. 22). 
Por último, vinha o estudo das conjunturas e dos acontecimentos de média e curta duração - o tempo social e individual - que se destinava ao $2^{\circ}$ grau, o qual deveria ser trabalhado por disciplinas, focalizando o eixo: "O homem" - "A sociedade no tempo", analisados "nos diversos aspectos estudados pelas Ciências Sociais" (UFPR, 1976/1977, p. 46-57) ${ }^{18}$.

Desse modo, a partir do eixo central - o homem em sociedade - e das variáveis tempo e sociedade, definiram-se as matrizes geradoras, coerentes com a multiplicidade temporal, as quais foram revisadas no experimento da $3^{\text {a }}$ fase, em 1977, no que se refere ao ensino da $1^{\mathrm{a}}$ à $8^{\mathrm{a}}$ série $^{19}$ :

- "realidades de longa, muito longa duração", que constituem as tendências seculares a serem estudadas como atividades através dos temas: "as necessidades básicas do homem”; “a vida de todos os dias" (1 $1^{\mathrm{a}} 2^{\mathrm{a}}$ e $3^{\mathrm{a}}$ série); "necessidades básicas do homem brasileiro" ( $4^{\mathrm{a}}$ série);

- "estruturas de longa duração", estudadas como áreas de estudo com os temas: "as sociedades" ( $5^{\text {a }}$ série); "o trabalho e as técnicas" ( $6^{\text {a }}$ série); "os espaços, as economias e as trocas" ( $7^{\mathrm{a}}$ série) e "as ciências" ( $8^{\mathrm{a}}$ série);

- "conjunturas, acontecimentos de média ou curta duração", estudadas como disciplinas, através do tema: "o homem” ( ${ }^{\circ}$ grau) (UFPR, 1976/1977, p. 25, $35,74)$.

As matrizes geradoras, por sua vez, foram desdobradas em matrizes-base para cada série de ensino; e operacionais para os planos de ensino dos professores (UFPR, 1976/1977, p. 18).

Os planos de ensino eram elaborados por um grupo de pessoas - consultores, assessores, professores e alunos do curso de graduação em História da UFPR -, agentes que participavam do planejamento até a execução e avaliação, na fase da experimentação do Projeto. Essa centralização das decisões deve-se, de um lado, à exigência de controle da experimentação por parte dos pesquisadores, e, de outro lado, pelo imperativo da regulação social, no qual o domínio e a legitimação

18 Os intelectuais elaboraram o "modelo matricial", obedecendo a uma hierarquização de conteúdos e integração das Ciências Sociais "para todo o primeiro e o segundo graus", embora a rede municipal de ensino atendesse apenas o $1^{\circ}$ grau. Assim, para o $2^{\circ}$ grau é apenas indicada a matriz ampla - o homem -, com a observação de que seus temas poderão ser desdobrados e ampliados a partir dos níveis anteriores.

19 A primeira fase ocorreu em 1975, com experimento na $5^{\mathrm{a}}$ série; a segunda fase ocorreu em 1976 , com revisão do experimento da $5^{\mathrm{a}}$ série e sua adequação para a $4^{\mathrm{a}}$ série e ampliação para a $6^{\mathrm{a}}$ série; e a terceira fase, em 1977, com revisão dos experimentos anteriores, sua adequação e ampliação para as demais séries (UFPR, 1076/1977, p. 25). 
constituíam-se parceiros fundamentais. Tanto isso é verdade que a avaliação unificada não se realizava apenas nas escolas que desenvolviam o Projeto, mas era uma prática desenvolvida em todas as áreas do currículo e escolas municipais, sendo justificada pela racionalização e eficácia do ensino.

As [...] mais de 20 unidades escolares [...] tornavam imperiosa a existência do estabelecimento de padrões mínimos referentes à atuação discente em cada série de forma a permitir uma real proporcionalidade entre o nível escolar atingido e a aquisição dos conhecimentos necessários para a finalização do $1^{\circ}$ grau [...]. Adotou-se como solução uma avaliação unificada, baseada nos objetivos mínimos de cada bimestre [...] (Curitiba, 1975a, p. 15-16).

Embora a proposta não possa escapar a críticas, é possível perceber um esforço em manter a coerência teórico-metodológica. Ao propor-se o trabalho com as durações temporais e com a aproximação das Ciências Sociais, pretendia-se possibilitar uma leitura histórica global, viabilizando a reflexão sobre a realidade social em suas várias dimensões - econômica, histórica, geográfica, política e sociocultural. Esse princípio permitiria que a sociedade, inicialmente vista sob uma perspectiva local, pudesse gradativamente ser estudada de forma comparativa a outros recortes espaciais e temporais.

Não obstante, as mudanças introduzidas não podem ser consideradas indícios imediatos de transformações na prática escolar das escolas municipais. O ensino das Ciências Humanas, especialmente nas séries iniciais, dificilmente tem encontrado espaço para uma prática mais coerente, o que está diretamente relacionado com a formação do professor, com o acesso à informação e com as condições do trabalho escolar.

\section{A RENOVAÇÃO METODOLÓGICA NA MEMÓRIA DOS PROFESSORES}

O que teria ocorrido no cotidiano da sala de aula com os Estudos Sociais? Haveria indícios de renovação metodológica nessa prática? Ao serem indagados sobre as práticas escolares realizadas no cotidiano escolar, os entrevistados não deixaram de mencionar prioritariamente a estruturação por objetivos das propostas curriculares. Registrou-se, na memória de alguns dos depoentes, que, mesmo o Projeto, que teria uma finalidade intelectual, visando ao exercício de certa razão crítica, instigando o aluno a uma análise mais contextualizada, embora não tivesse a crítica marxista ou a crítica ao sistema, trazia, entretanto, a característica 
tecnicista de uma das orientações pedagógicas dominantes naquele contexto, que se revelava na ênfase ao planejamento e à avaliação por objetivos e no processo pedagógico pautado por técnicas de ensino.

O projeto estava vinculado àquela questão de educação por objetivos. Eu tenho uma vaga idéia... de uma coisa meio misturada que acontecia [...]. De um lado o Projeto da longa duração que pelo que eu compreendo [...] era uma coisa mais de análise contextualizada, até mesmo de uma análise crítica, embora não tivesse a crítica marxista ou a crítica ao sistema, mas desenvolvia o raciocínio crítico do aluno. [...]. E que não batia muito com o processo de [...] avaliação por objetivos. Isso sempre me perturbou. $\mathrm{E}$ a prática de sala de aula era a época do modismo de ensinar-aprender por dinâmicas de grupo (Entrevistado "C", 12/05/o6).

A forte influência do planejamento é um traço destacado por Gonçalves como uma das diretrizes da Escola Superior de Guerra (ESG) para a tomada de decisões, seja no campo político, seja no técnico, tendo em vista as finalidades de desenvolvimento econômico e social:

Cabe [...] ressaltar o detalhamento acerca do Planejamento, definido como "a atividade permanente e continuada, que se desenvolve de modo ordenado e racional, sistematizando um processo de tomada de decisões" (ESG, 1975, p. 537), que abrange ações políticas e técnicas. Quando envolver "atividades de setores ou órgãos diversos, mas interdependentes, persiste não só a necessidade de coordenação, mas também a de integração das ações planejadas pelos diversos setores" (ESG, 1975, p. 538, apud GonçALVES, 2012, p. 14).

A finalidade de constituição de uma cidadania social mais ampla ficava limitada pelo quadro geral dos dispositivos estratégicos da regulação social, que se orientava mais por interesses políticos da modernização conservadora, centrada na ideia de progresso e de estratégias de racionalização e controle, tendo em vista o desenvolvimento do capitalismo, do que pelo interesse em desenvolver uma formação sólida e a capacidade intelectual dos alunos.

Assim, cabe pensar se o Projeto permitiu a reorientação dos “fazeres ordinários" (CERTEAU, 1994) na sala de aula. Ele teria garantido efetivamente a concretização de uma alternativa ao projeto educativo oficial de Estudos Sociais, reorientando a prática escolar, como pressuposto inicialmente? 
O discurso prescritivo do Projeto propunha o desenvolvimento intelectual do aluno, defendendo que a "estrutura da matéria de Estudos Sociais favorece(ria) uma série de operações: observar, relacionar, relatar, experimentar, induzir, colecionar, comparar, analisar, inferir e extrapolar" (UFPR, 1976/1977, p. 100). Esse interesse estava implícito também na concepção de aluno, em sua representação como sujeito ativo: "o princípio da atividade do aluno, no sentido de ser este o principal agente na construção do conhecimento de sua própria aprendizagem” (UFPR, 1076/1977, p. 100).

O depoimento de uma professora, em relatório da escola acerca de sua experiência com o Projeto, revela, com efeito, a aplicação desse princípio ativista para alcançar o desenvolvimento do aluno, com ênfase na exploração do cotidiano da criança, e também aponta indícios de uma preocupação com a aquisição de conceitos, já nas séries iniciais:

[...] partimos do cotidiano do aluno, daquilo que ele tem conhecimento para o desconhecido e depois para a elaboração dos conceitos [...]. Em comparação com as turmas tradicionais, das quais também sou professora, em outro estabelecimento, as turmas do Projeto apresentam uma capacidade de elaboração de conceitos e formação de frases superior e em tempo mais curto (CuRITIBA, 1976, p. 1).

Os pressupostos da escola nova estavam presentes em várias fontes, orientando o discurso e a prática escolar, perpassados por elementos da pedagogia tecnicista. "Era a escola nova. E eu também fui uma pessoa empolgada. Então, a gente usava muitas práticas de dinâmica de grupo [...], entrando no meio deles para discutir determinados temas, elaborar algum trabalho, corrigir exercícios" (Entrevistado "C", 12/05/06).

Outra estratégia metodológica registrada pelos depoentes era a "pesquisa", que aparece tanto na fala dos professores como nos relatórios de atividades das escolas. Entretanto, que caráter tinha essa pesquisa?

Na memória de um dos entrevistados, "eram pesquisas bibliográficas, limitadas pelas condições estruturais da escola pública, cuja biblioteca possuía um acervo precário. E, também, não era uma prática comum a todos" (Entrevistado "C", 12/05/06). Sob a forma de microrresistências, alguns professores colocavam-se em uma situação de acomodação e de conservação das práticas tradicionais, recusando-se a qualquer alteração em seus fazeres. Afirma o professor: 
[...] acho que foi até um trabalho interessante de fazer a criança ir à biblioteca, fazê-la ler, ter a capacidade de fazer a síntese, mas [...]. Recordo [...] tinha professores que faziam isso [...] e professoras que não faziam ou negavam-se a fazê-lo (Entrevistado "C", 12/05/o6).

O Entrevistado "B”, entretanto, recupera outro significado para a prática de pesquisa - a empiria -, o método experimental. Por meio dele tentava-se, por exemplo, conduzir a criança à compreensão da noção temporal, na perspectiva de superação da concepção tradicional de tempo cronológico na História, desenvolvendo sua capacidade de observação:

Eu cheguei a fazer bolinhos para que eles [refletissem], [...] coloca[va] o trigo dentro da tigela. E aí a gente perguntava: que material era aquele da tigela? Será que sempre foi aquela tigela? [...] Daí eles voltavam no tempo [...] analisavam comigo outros materiais usados em outros tempos [...] (Entrevistado “B”, 07/03/06).

As crianças eram instigadas a pensar, a estabelecer relações entre o presente e o passado, buscando as permanências e mudanças, embora aqui também se perceba uma ênfase exclusiva na apropriação do cotidiano ${ }^{20}$. Elas eram, também, incentivadas a realizar observações, coletar informações, a se manifestarem oralmente e a sistematizarem na escrita o que tinham discutido. "Pesquisávamos dentro da comunidade também, não era só pesquisa bibliográfica [...]. Encaminhávamos os alunos para realizar entrevistas e observações em espaços da comunidade” (Entrevistado “B”, 07/03/06). Essa professora e outra depoente das séries iniciais relatam o caso da visita a um estabelecimento comercial para observar suas condições de higiene, despertando a curiosidade e a vontade de mudança de atitudes nas crianças e, por extensão, em sua família.

- Lembra que você mandou irem ao açougue? Conta do açougue [risos]. A Vila estava bem no início, faltava higiene no açougue (Entrevistado “A”, 07/03/06).

20 A leitura que influenciava essa abordagem era a de Braudel (1970), que discutia a noção de civilização e vida material, em que o cotidiano tinha um papel significativo por este historiador acreditar que nele mais facilmente seriam apreendidas as regularidades sociais. A apropriação do texto do historiador francês era reforçada na visão dos educadores pelo viés empírico da Psicologia da Aprendizagem. 
- É verdade [...]. Mandei meus alunos para realizarem uma observação ao açougue [...]. Lembro que eles voltaram contando da falta de higiene, das moscas que estavam ao redor daquela carne e se perguntando: como é que nós iríamos comer aquela carne [...]? Eles [...] traziam essas informações, e depois a gente trabalhava com isso, discutindo higiene, alimentação (Entrevistado “B”, 07/03/o6).

- E depois eles iam lá, no açougue, discutir com o açougueiro! [risos]. [...] ele mudava a si mesmo e ao meio dele [grifo nosso]. Essa era a beleza! De mudar a comunidade dele. Já não aceitava pegar as coisas com a mão suja, já não aceitava que lhe dessem um pão, pegando-o com a mão... (Entrevistado “A”, 07/03/06).

Os conteúdos nas aulas de Integração Social, para as crianças das séries iniciais, confundiam-se com os conhecimentos das Ciências Naturais. Não nos esqueçamos de que a estratégia política era integrar também as áreas de conhecimento, desde que houvesse afinidade nos conteúdos.

Mas o que é significativo na fala dos depoentes é que ela já evidencia uma tentativa de formar o aluno, senão para uma prática de pesquisa sistemática, para uma prática de observação, usando também o recurso de entrevistas, embora nos limites do empírico, da faixa etária, do nível de ensino com os quais trabalhavam e das condições das escolas municipais.

Os depoimentos não permitem afirmar a presença de uma consciência clara sobre a relação de ensino e pesquisa, na escola de $1^{\circ}$ grau, como fio condutor da atividade pedagógica para a produção de um saber histórico escolar, como aparece em propostas pedagógicas mais recentes para o ensino de História. Mas, de qualquer modo, já constituíam alguns indicativos de esforço para que a prática escolar se transformasse.

Além disso, outro indício do interesse para a pesquisa e o uso do método histórico no ensino é encontrado já em anos anteriores, em comunicação apresentada por Westphalen (1968), coordenadora geral do Projeto.

Poderá objetar-se que a quase totalidade dos estudantes dos cursos superiores de História, no país, destina-se ao magistério de grau médio e não à pesquisa histórica. No entanto, seria um grave erro pensar que os professores de História não devem receber treinamento para a pesquisa, pois que o manejo do método é que pode conduzir à compreensão de como os historiadores trataram e escreveram a História, e, pois, a sua melhor explicação e ensino. De outro lado, todo 
professor deve ser um pesquisador, qualquer que seja o grau de seu magistério (grifo nosso) (WeSTPHALEN, 1968, p. 80).

Com efeito, havia vestígios táticos para a superação da prática tradicional, no sentido de orientar o aluno para a reflexão sobre a realidade que o circundava, para o desenvolvimento da capacidade de buscar informações já produzidas ou não e para sistematizá-las. A prática de pesquisa, nesse sentido, a preocupação com a aquisição de uma linguagem conceitual e a finalidade do ensino voltada à autonomia intelectual do aluno não apareciam no projeto educativo oficial com a visibilidade com que se destacavam no projeto alternativo.

Contudo, essas práticas não se constituíram como regra geral, pois dependiam da formação do professor e de seu modo de apropriação das “inovações" apresentadas. A leitura dos relatórios das escolas, por exemplo, confirmam a assertiva, pois, enquanto alguns traziam uma crítica ao procedimento metodológico da pesquisa, alegando que os alunos das escolas municipais não tinham condições para sua realização em suas casas (atribuindo a dificuldade à condição social do aluno), outros evidenciavam uma apropriação contraditória do disposto no discurso prescritivo do Projeto, alegando que os objetivos e conteúdos dos Estudos Sociais não favoreciam atividades com pesquisas (CuRitiba. Relatórios das escolas, 1979; 1984).

Outros aspectos negativos sobre o Projeto foram apontados por professores das séries iniciais, como os que concernem: à complexidade dos objetivos, dos conteúdos e da metodologia; à linguagem inacessível à criança e difícil para o professor; à falta de tempo para o preparo das atividades; à extensão dos conteúdos; ao pouco tempo para trabalhar em sala de aula; à ausência de livros didáticos naquela concepção; à dificuldade para o professor realizar pesquisas para suas aulas; ao tempo tomado pela área, prejudicando o ensino de outras (CURITIBA. Relatórios de escolas, 1978; 1979a; 1984). Ressalte-se que nem sempre o professor das séries iniciais tinha formação superior, e muito menos em História.

Apesar das críticas, registros positivos permaneceram na memória dos depoentes. Esses indícios evidenciam o quanto o Projeto havia afetado professores e alunos. O relato do Entrevistado "C" indica a forte influência em sua própria formação:

$\mathrm{Eu}$, pessoalmente, posso confessar que foi talvez a coisa que mais mexeu comigo como professor de História, porque até aí eu também tinha uma visão muito factual da História. Depois [...] eu fui caminhar por uma linha mais marxista da História [...]. Mas essa época isso me encantou, porque me dava uma perspec- 
tiva de visão de educação e da objetividade da História que antes eu não tinha (Entrevistado “C”, 12/05/o6).

Os depoimentos dos Entrevistados "A" e "B" (Entrevista em 07/03/06) são reveladores, no sentido da incorporação conceitual por parte dos alunos na prática escolar, assim como no desenvolvimento de sua capacidade criativa, interesse pelo conhecimento e pelo exercício de raciocínio e de julgamento.

[...] a gente pôde observar isso nos alunos. Nossa, a mudança! Eles eram crianças que perguntavam, julgavam, elas tinham interesse em buscar informações (grifo nosso). Acabou a “decoreba”! [...] Antes era assim: você apresentava o ponto: Descobrimento do Brasil, Pedro Álvares Cabral, 1500, [fazia um] questionário de cinco perguntinhas ou dez. [...] a gente trabalhava com muita cartolina, recortes, discutia os conceitos e após aqueles trabalhos chegava a alguma conclusão, os alunos produziam um texto [...]. Foi uma revolução na cabeça do professor, também... (Entrevistado “A”, 07/03/06).

O interesse da criança era diferente! Interesse de raciocinar. [...] Então, era enfadonho para o aluno estudar "aquela” História e "aquela” Geografia [tradicionais]. Quando nós começamos com isso, [...] que reação os alunos tiveram [...] de busca, de discussão, de procurar fazer. E não tinha livro. Eles não precisavam decorar nada [...] [era] uma nova aprendizagem. Tanto para eles, como para nós professores. Eu me vi, assim, mais valorizada! (Entrevistado “B”, 07/03/o6).

Eles confirmam alguns resultados alcançados pelas escolas e relacionados em Relatório do Departamento de História (UFPR), acerca do Projeto. Entre eles destacam-se: aumento da criatividade nos trabalhos das crianças; maior estímulo por parte dos professores para transmitir o conteúdo; aquisição dos conceitos trabalhados, cujo resultado aferido na avaliação demonstrou um aproveitamento superior a 70\%, para a maioria dos alunos; a metodologia desenvolvida permitiu não só a elaboração de conceitos, como, em alguns casos, levou a inferências e deduções; houve presença da pesquisa como estratégia de ensino, no sentido de busca e interpretação de dados e formação de atitudes (UFPR, n. 2, 1976/1977, p. 84). 


\section{CONSIDERAÇÕES FINAIS}

Da análise do Projeto e de seu desenvolvimento pôde-se inferir que determinados professores o aceitaram entusiástica ou passivamente, e mesmo os que o aceitaram enfrentaram dificuldades de apropriação, o que gerou procedimentos táticos variados de enfrentamento às ordenações, como resistir às mudanças, negociar com elas ou fazer críticas diversas, até negando-se a incorporá-las. As atitudes de microrresistência se concretizaram, por exemplo, na permanência de uma postura conservadora, de "ranço" tradicional - "alguns professores preferiam passar o ponto de História e de Geografia, separadamente, no quadro para os alunos, transformando a aula em outra coisa que não Estudos Sociais", como desvelam as "escrituras invisíveis" (CERTEAU, 1994) da memória do Entrevistado "C" (Entrevista em 12/05/06).

Esse professor também se recorda da pouca participação dos professores municipais em eventos políticos mais amplos, mesmo no campo educacional, como o próprio movimento pelo retorno da História e Geografia ao currículo do $1^{\mathrm{o}}$ grau, liderado localmente pelos próprios técnicos da administração educacional, segundo o entrevistado (Entrevista em 12/05/06). Mas esse processo ocorreu já em outro contexto histórico, o do percurso da redemocratização político-social do país, quando um movimento de reação mais organizado se desenvolveu, em meados dos anos 1980, com a incorporação dos professores municipais ao debate nacional que se organizava pelo retorno das disciplinas autônomas.

Os atos de resistência na escola expressavam muito mais a luta de representações sobre a prática pedagógica do que atos de rebeldia às políticas - educacional e social. Embora os professores as olhassem com desconfiança, eles não se mobilizaram de imediato contra o poder central. Suas táticas limitaram-se ao seu não lugar, ficaram restritas às microações articuladas contingencialmente no lugar praticado, ou seja, no interior da escola e da sala de aula. Os registros na memória dos professores demonstram que as "artes de fazer" no cotidiano da escola, nos moldes de uma "caça não autorizada", como nomeia Certeau (1994, p. 38), constituíam-se na sucessão de pequenas ações de resistência, (re)apropriações, adequações, negociações, reinventando os usos e procedimentos com os bens culturais, mas sem afetar de imediato a organização coletiva de poder.

Por outro lado, embora o período se caracterize como de autoritarismo e repressão, criando múltiplas estratégias de controle e dominação, como a própria institucionalização da área de Estudos Sociais no ensino de $1^{\circ}$ grau e a supressão de disciplinas escolares mais críticas do currículo do ensino de $2^{\circ}$ grau, como a 
Filosofia e a Sociologia, os estudos sobre o período revelam que nem sempre as estratégias políticas do regime militar se revelaram com força suficiente para sua concretização efetiva, havendo, no campo educacional, por exemplo, uma margem de negociação que permitiu aos educadores enfrentarem esse período com o uso de táticas diversas, seja de adesão parcial, reinvenção, seja de resistência passiva.

Esse foi o caso não só dos professores municipais como dos próprios intelectuais envolvidos naquele Projeto, os quais, chamados a participar do processo de legitimação de uma estratégia política governamental, prática usual naquele contexto, optaram por uma tática específica de (re)orientação da ordem legal. Fundamentando cientificamente o projeto governamental, deram-lhe relativa legitimidade, porém atenderam também aos interesses acadêmicos e conduziram-no a uma proposta educativa alternativa à oficial, embora ainda relativamente conservadora, entretanto, mais coerente com os interesses de desenvolvimento educacional na época.

Esse projeto educativo, parcialmente aceito pelos professores, teve dificuldade de apropriação, a tal ponto que, apenas uma década depois de sua implantação, foi deixado de lado. Já, então, entrou em curso outro contexto histórico, político e educacional, apresentando exigências mais complexas.

\section{REFERÊNCIAS BIBLIOGRÁFICAS}

Aвud, K. M. O ensino de história como fator de coesão nacional: os programas de 1931. Revista Brasileira de História, São Paulo: ANPuH, v. 13, n. 25/26, p. 163-174, setembro 1992/agosto 1993.

ApPLE, M. W. A política do conhecimento oficial: faz sentido a idéia de um currículo oficial?

In: Moreira, A. F.; Silva, T. T. (Org.) Currículo, cultura e sociedade. São Paulo: Cortez, 1995. p. 59-91.

Bittencourt, C. M. F. Propostas curriculares de história: continuidades e transformações.

In: BARreto, E. S. D. As propostas curriculares oficiais. São Paulo: Fundação Carlos Chagas, 1995. p. 97-114.

Brasil. CFE. Parecer nº 7.676/78. Revista Documenta, Brasília, MEC, n. 217, dez. 1978. Parecer $\mathrm{n}^{\circ}$ 785/86, anexo à Resolução ${ }^{\circ}$ 06/86. In: RANGEL, M. Currículo de $1^{\circ}$ e $2^{\circ}$ graus no Brasil. Petrópolis: Vozes, 1988.

BRAUdEL, F. Civilização material e capitalismo. Lisboa: Cosmos, 1970.

. História e Ciências Sociais. Lisboa: Editorial Presença, 1972.

Certeau, M. A invenção do cotidiano - 1. Artes de fazer. Petrópolis, Rio de Janeiro: Ed. Vozes, 1994. 
A invenção do cotidiano - 2. Morar, cozinhar. Petrópolis, Rio de Janeiro: Ed. Vozes, 1996.

ChARTIER, R. A história cultural. Entre práticas e representações. Lisboa: Difel, 1986. O mundo como representação. Estudos Avançados, São Paulo, v. 5, n. 11, jan./abr. 1991.

Chevallard, Y. La transposición didáctica. Buenos Aires: Aique, 1991.

Curitiba. Prefeitura Municipal de. Departamento de Bem Estar Social. Diretoria de Educação. Relatório Geral de Atividades. Curitiba, 1975a.

. Prefeitura Municipal de. Departamento do Bem Estar Social. Diretoria de Educação. Plano Curricular. Volumes III-A e III-B. Curitiba, 1975b.

. Prefeitura Municipal de. Departamento do Bem Estar Social. Diretoria de Educação. Relatório das Escolas. Escola Omar Sabbag. Atividades de Estudos Sociais, Curitiba, 1976.

Prefeitura Municipal de. Diretoria de Educação. Relatórios das escolas. Atividades de Estudos Sociais. Curitiba, 1978.

Prefeitura Municipal de. Diretoria de Educação. Relatórios das escolas.

Atividades de Estudos Sociais. Curitiba, 1979a.

. Prefeitura Municipal de. Diretoria de Educação. Relatório Anual. Curitiba, $1979 \mathrm{~b}$

. Prefeitura Municipal de. Diretoria de Educação. Relatório Anual. Curitiba, 1982.

Prefeitura Municipal de. Diretoria de Educação. Relatórios das escolas. Atividades de Estudos Sociais. Curitiba, 1984.

Prefeitura Municipal de. Secretaria Municipal de Educação. Plano de Educação da Secretaria Municipal de Educação para a gestão 1986-1988. Curitiba, 1986.

. Prefeitura Municipal de. Secretaria Municipal de Educação. Currículo Básico

- Uma contribuição para a Escola Pública Brasileira, 1988.

Entrevistado “A”. M. E. A. Professora aposentada da Rede Municipal de Ensino de Curitiba.

Entrevista concedida à Iêda Viana. Fita Magnética. Curitiba, 07 de março de 2006.

Entrevistado “B”. E. T. Professora aposentada da Rede Municipal de Ensino de Curitiba.

Entrevista concedida à Iêda Viana. Fita Magnética. Curitiba, o7 de março de 2006.

Entrevistado "C". A. H. S. Ex-professor da Rede Municipal de Ensino de Curitiba.

Entrevista concedida à Iêda Viana. Fita Magnética. Curitiba, 12 de maio de 2006.

Fenelon, D. A questão dos Estudos Sociais. Cadernos Cedes. A prática do ensino de história, São Paulo: Cortez/CEDEs, n. 10, p. 11-22, 1984.

FonseCa, S. G. Caminhos da História Ensinada. 3. ed. Campinas, São Paulo: Papirus, 1995. 
GonçAlves, N. G. A Escola Superior de Guerra e a Lei 5.692/71: discursos governamentais e implementação da Lei no Paraná. In: Gonçalves, N. G.; Ranzi, S. F. (Org.) Educação na ditadura civil-militar: políticas, ideários e práticas (Paraná, 1964-1985). Curitiba: Editora UFPR, 2012. p. 10-28.

Hirst, P. H.; Peters, R. S. A lógica da educação. Rio de Janeiro: Zahar Editores, 1972.

Julia, D. A cultura escolar como objeto histórico. Revista Brasileira de História da Educação, Campinas: Autores Associados, n. 1, p. 09-43, 2001.

Malinowski, B. Uma teoria científica da cultura. Rio de Janeiro: Zahar, 1962.

NADAI, E. A escola pública contemporânea: os currículos oficiais de História e ensino temático. Revista Brasileira de História, São Paulo, v. 6, n. 11, p. 99-116, set.1985/ fev. 1986.

. O ensino de História no Brasil: trajetórias e perspectivas. Revista Brasileira de História da Educação, São Paulo: ANPUH, v. 13, n. 25/26, p. 143-162, set.1992/ ago.1993.

PARANÁ. CEE. Parecer $n^{0}$ 332/84. 1983.

Deliberação ${ }^{\circ}$ oo47/87. 1987.

Popkewitz, T. S. Reforma educacional - uma prática sociológica. Porto Alegre: Artes Médicas, 1997.

Presseisen, B.; D’Amico, J. A Functional Social Studies Curriculum Ephasizing Piagetian Operations. In: The Educational Forum, (39)2. Chicago, Ed. Kappa Delta Pi, Janeiro 1975. p. 163-175. In: Universidade Federal do Paraná. Setor de Ciências Humanas, Letras e Artes. Departamento de História. Projeto de Estudos Sociais a partir da longa duração. Curitiba: UFPR/Dehis, 1976/1977. 3 v. p. 450.

Schmidt, M. A.; Cainelli, M. R. Ensinar História. São Paulo: Scipione, 2004.

Universidade Federal do Paraná. Setor de Ciências Humanas, Letras e Artes. Departamento de História. Projeto de Estudos Sociais a partir da longa duração. 3 v. Curitiba: UFPR/Dehis, 1976/1977.

VIANA, I. "Artes de fazer" na reforma escolar: o projeto de estudos sociais a partir da longa duração em Curitiba (décadas de 1970-1980). 236 p. 2006. Tese (Doutorado em História e Historiografia da Educação) - Setor de Educação/ UFPR. Curitiba, 2006. Westphalen, C. M. A introdução ao estudo da História e as técnicas auxiliares do historiador. In: Simpósio Nacional dos Professores Universitários de História, 5. São Paulo, 07/07/1968 a 09/07/1968. Universidade de São Paulo. Faculdade de Filosofia, Ciências e Letras. Anais... São Paulo: USP, 1968.

Recebido para publicação em 28/01/2014. Aceito para publicação em 20/02/2014. 